\title{
0254 ROAD TRAFFIC FATALITIES AMONG CHILDREN IN
} GHANA

W Ackaah* Correspondence: CSIR - Building and Road Research Institute, University P. 0. Box 40, KNUST, Kumasi, Ghana

10.1136/ip.2010.029215.254

Objective The key objective of the study was to establish the characteristics of fatal road traffic crashes involving children ( $\leq 15$ years) and to recommend measures to control them.

Materials and Methods Crash data for the period 2004-2008 in Ghana were analyzed using the micro-computer accident analysis package (MAAP) software. Recently published transport-related epidemiological and other studies provided additional data sources.

Results Slightly over 9800 people were killed in road traffic crashes in Ghana during the 5-year period of which $19 \%$ were children. Majority (79\%) of the children who died from these crashes were pedestrians. The child-pedestrian constituted $34 \%$ of all pedestrian fatalities. It was established that $76 \%$ of the children were hit by vehicles while crossing the road and were more likely to be boys (54\%) than girls (46\%). Compared to a child car-occupant, a child-pedestrian is about 20 times likely to die in a crash and majority (57\%) of these crashes occurred on high speed roads passing through village settlements.

Conclusions and Recommendations A high number of children are at risk in traffic as pedestrians and are most likely to be killed on high speed roads in the non-urban setting. Education on road safety for children must be directed at those living in village communities along the major highways. Road engineers and planners should redesign the village road sections to calm traffic and make conscious efforts to integrate safer pedestrian facilities in new and existing roads in Ghana. 